Direitos autorais distribuídos a partir $\mathrm{d}$ licença Creative Commons (CC BY-NC-SA - 4.0)

\title{
A COSMICIDADE DA CASA: SEUS MITOS E IMAGENS NO FILME MÃE!, DE DARREN ARONOFSKY
}

\author{
Adriano Menino de Macêdo Júnior - adrianomenino2016@gmail.com. \\ Universidade do Estado do Rio Grande do Norte, UERN, Mossoró, Rio Grande do Norte, Brasil; \\ https:/ / orcid.org/0000-0001-6367-1088 \\ Roniê Rodrigues da Silva - ronierodrigues@uern.br \\ Universidade do Estado do Rio Grande do Norte, UERN, Mossoró, Rio Grande do Norte, Brasil; \\ https://orcid.org/0000-0002-2738-7087
}

\begin{abstract}
RESUMO: Este trabalho objetiva realizar uma leitura crítica do filme Mãe!, dirigido por Darren Aronofsky e lançado nos Estados Unidos no ano de 2017. De maneira específica, visa problematizar como a narrativa fílmica reencena uma série de mitos da literatura universal, que se desenrolam na versão cinematográfica considerando o simbolismo do território da casa, a qual é compreendida como um universo particular que se relaciona com uma significação cósmica, por meio da qual passa a representar o próprio mundo. No desenvolvimento das nossas reflexões, recorremos aos estudos no campo da mitologia, a partir da leitura de teóricos como Mircea Eliade (2007) e Philip Freund (2008), e a respeito do simbolismo do centro, através das pesquisas de Raissa Cavalcanti (2008) e Chevalier e Gheerbrant (2009), para destacar as relações dialógicas entre o enredo de Mãe! e determinados arquétipos literários. Particularmente, aprofundamos, ainda, a abordagem em torno das imagens da casa, realizando uma análise fenomenológica de seus lugares vitais com o auxílio teórico de Gaston Bachelard (2000), para demonstrar como no filme a arquitetura da morada se erige a partir de uma polaridade entre os espaços do alto e do subterrâneo.
\end{abstract}

PALAVRAS-CHAVE: Darren Aronofsky; Mãe!; mitos; casa.

\section{INTRODUÇÃO}

O termo alegoria (do grego "allegoría", que significa "dizer o outro”) pode ser compreendido como uma palavra filosófica e de natureza retórica. Considerada como uma forma de expressão do pensamento, é representada através de muitas linguagens como por meio de filmes, músicas, desenhos, pinturas, literatura, etc. (BÜHLER, 2019). Em outras palavras, quando nossos pensamentos e ideias são expressos de forma figurada podemos chamar de alegoria. (SILVA \& FALÇÃO, 2019). A partir dessa noção, objetivamos, ao longo desse trabalho, problematizar como alegoricamente se representa a reencenação de determinados mitos da literatura universal, destacando como a obra cinematográfica contemporânea conta histórias que remontam às memórias primordiais da coletividade humana, suas crenças sobre a origem do cosmo e da vida.

De maneira específica, a leitura em tela gira em torno do filme Mãe!: uma narrativa desenvolvida a partir do gênero suspense ou terror psicológico, escrita e dirigida por Darren Aronofsky. O referido longa-metragem foi lançado nos Estados Unidos no ano de 2017 pela Paramount Picture e no elenco conta com a presença de atores consagrados, tais como Jennifer Lawrence, Javier Bardem, Michelle 
Pfeiffer, Ed Harris e Kristen Wiig. Seu enredo gira em torno de um casal, um personagem masculino reconhecido pela função de escritor/poeta, e que seria uma espécie de simulacro de Deus; e sua esposa, que na intriga corresponde à mãe natureza. Ao longo da trama, a história retoma importantes arquétipos mitológicos por meio de uma linguagem alegórica que dialoga, por exemplo, com os relatos bíblicos, desde o Antigo até o Novo Testamento, para representar protótipos divinos de territórios, particularmente relacionados ao espaço da casa, onde todas as ações da obra cinematográfica de Aronofsky se desenrolam.

Nesse sentido, procuraremos demonstrar, ao longo de nossa análise, de que maneira a casa aparece ficcionalizada como um universo particular que se associa a uma significação cósmica, a partir da qual passa a representar no filme o próprio mundo, um modelo de um espaço vital. Para nortear a nossa compreensão a respeito de um simbolismo dos arquétipos celestiais de territórios, recorremos às reflexões teóricas no campo da mitologia, seguindo principalmente os estudos de Mircea Eliade (2007) e Philip Freund (2008) sobre os mitos da criação, os processos de transformação implicados na passagem do caos para o cosmo, os rituais de edificação que repetem o ato primordial da construção cosmogônica e o prestígio do centro como lugar no qual se origina a fundação do universo.

Visando aprofundar a leitura sobre os sentidos das imagens da casa em Mãe!, realizamos ainda uma análise fenomenológica de seus lugares vitais com o auxílio teórico de Gaston Bachelard (2000), para demonstrar como no filme a arquitetura da morada se erige a partir de uma polaridade entre os espaços do alto, que representaria uma espécie de sótão, e do baixo, simbolizado pelo porão.

\section{IMAGENS MÍTICAS REVISITADAS NA ESPACIALIDADE DA CASA}

Em seu estudo sobre os mitos da criação, o antropólogo Philip Freund (2008) observa uma estreita relação entre as histórias nas quais se narra o ato cosmogônico e aquelas em que se representam os mitos escatológicos. A respeito desses últimos, ele destaca que "São, no entanto, um pano de fundo necessário para as histórias da criação e quase sempre estão acoplados a elas”. (FREUND, 2008, p. 18).

Este motivo-mito, a partir do qual se desenrola uma passagem do caos para o cosmo, faz parte do imaginário de muitas culturas, que acreditam que o mundo teria se originado a partir de uma realidade inóspita, uma catástrofe ou sacrifício que ocorre no momento de fundação da existência e que acabou por se transformar num dos mais representativos arquétipos literários do ritual de construção.

É a partir desse repertório primordial de imagens, pelo qual identificamos determinados padrões, paradigmas ou ideias relacionadas à existência de todas as coisas, que se inicia o filme Mãe! dirigido por Darren Aronofsky, lembrando que cada narrativa cosmogônica é precedida por outra de natureza escatológica. Seguindo esse raciocínio, o enredo fílmico se principia com a personagem da mãe natureza, 
interpretada pela atriz Jennifer Lawrence, envolta em chamas, circundada por um grande incêndio, que representa na história da obra cinematográfica uma combustão universal, demarcando o fim de uma temporalidade, conforme observamos pelo recorte abaixo:

Figura 1 - Mãe natureza envolta em chamas

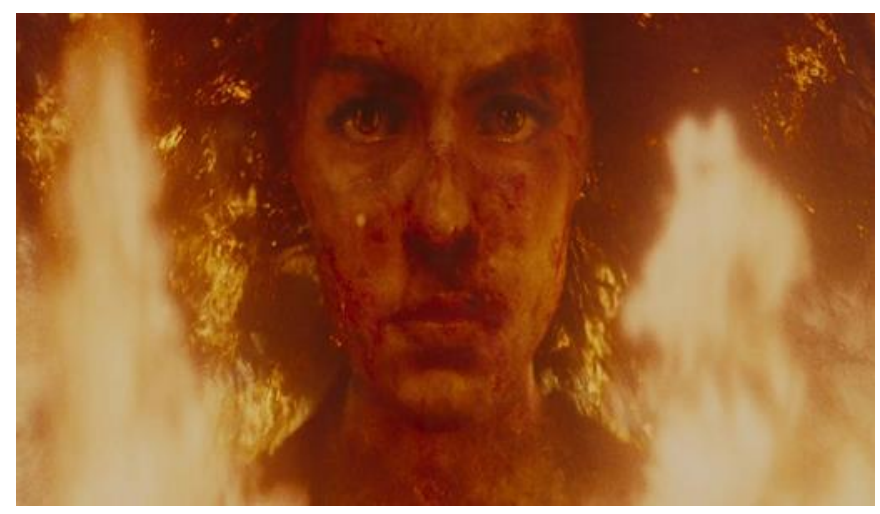

Fonte: Mãe! (2017)

Consoante se nota, a imagem do cataclismo cósmico é constituída no filme a partir de um sacrifício que se realiza pela presença do fogo, elemento recorrente nos mitos apocalípticos, conforme destacam estudiosos como Eliade (2007) e Freund (2008). De acordo com os dois mitólogos, ao fogo se associam uma infinidade de narrativas escatológicas nas quais o mundo se acabaria como consequência de um grande incêndio: "Estes não são mitos da criação, mas mitos de catástrofes. (...) Falam de um terrível incêndio, ao mesmo tempo cósmico e terreno". (FREUND, 2008, p.18).

Chevalier e Gheerbrant (2009, p. 441) lembram, igualmente, a natureza destruidora do fogo e sua presença em histórias de escathon, relacionando o elemento ao universo do mal e a um agente negativo que seria responsável pela conflagração do mundo. Seguindo esse raciocínio, para a cultura judaico-cristã, por exemplo, o fogo seria, em algumas leituras, um componente pertencente ao domínio de Lúcifer, anjo decaído e outrora portador da luz celeste. Todavia, por outro lado, no próprio texto bíblico, observamos o fogo sendo utilizado também por Deus em diferentes ocasiões para determinar a consumação de uma dada realidade, como no caso de Sodoma e Gomorra; e na narrativa do Apocalipse, em que se relata o encerramento de uma temporalidade.

É nesse contexto de encerramento de um ciclo que, na narrativa fílmica, a imagem do incêndio é retomada em outra cena pelas palavras do personagem Him, vivido pelo ator Javier Bardem, que aparece na história exercendo a função de um escritor/poeta e esposo da protagonista feminina. No diálogo desenvolvido com o personagem de Ed Harris, sem cognominação e identificado apenas pelo ofício de médico ortopedista, Him explica que havia perdido toda a sua última criação em um grande incêndio, mas que teria tido a chance de começar tudo novamente, apontando, por meio de sua fala, para a 
reencenação do mito do eterno retorno e da concepção do tempo circular, a partir do qual a trama do filme se erige, aludindo a uma sucessão de ciclos. Essa ideia é reforçada pelo fato de as ações da narrativa se desenrolarem no espaço de uma casa em reforma/(re)construção, localizada no meio do nada, representando mais uma passagem do caos para o cosmo.

Essa leitura torna-se coerente na medida em que, no filme de Darren Aronofsky, a casa retoma determinados arquétipos de territórios, simbolizando o próprio mundo. Nesse sentido, a sua (re)construção apontaria para a repetição do ato cosmogônico. De acordo com o mitólogo: “Os rituais de construção repetem o ato primordial da construção cosmogônica. O sacrifício praticado na construção de uma casa, igreja, ou ponte, é simplesmente a imitação, no plano humano, do sacrifício realizado in illo tempore, para dar nascimento ao mundo". (ELIADE, 2007, p. 35). Essa associação entre a construção de determinadas edificações e a reiteração dos mitos cosmogônicos é relembrada também por Raissa Cavalcanti (2008), quando observa que “A construção do templo, da cidade e, por extensão da casa do homem antigo era considerada a repetição de um ato cosmogônico de ordenação do mundo e, sendo assim, representava todo o universo". (CAVALCANTI, 2008, p. 45). A relação entre o território da casa com o do próprio cosmo é igualmente evocada por Bachelard em sua Poética do espaço, quando o estudioso realiza uma leitura fenomenológica dos lugares vitais, dos espaços habitados e nos quais localizamos a nossa intimidade: "Porque a casa é o nosso canto do mundo. Ela é, como se diz amiúde, o nosso primeiro universo. É um verdadeiro cosmos. Um cosmos em toda a acepção do termo”. (BACHELARD, 2000, p. 24).

Representada numa correlação com esses preceitos teóricos, em Mãe! a casa é, de fato, 'o canto do mundo', no qual os personagens protagonistas constituem as suas existências. Por isso, é a partir dela que a reencenação da cosmogonia é ratificada, sobretudo se considerarmos os diversos aspectos que aparecem relacionados à sua edificação como, por exemplo, a sua arquitetura e localização geográfica que podem ser associadas ao simbolismo do centro, conforme se percebe pela fotografia abaixo: 
Figura 2 - Casa localizada no centro do território

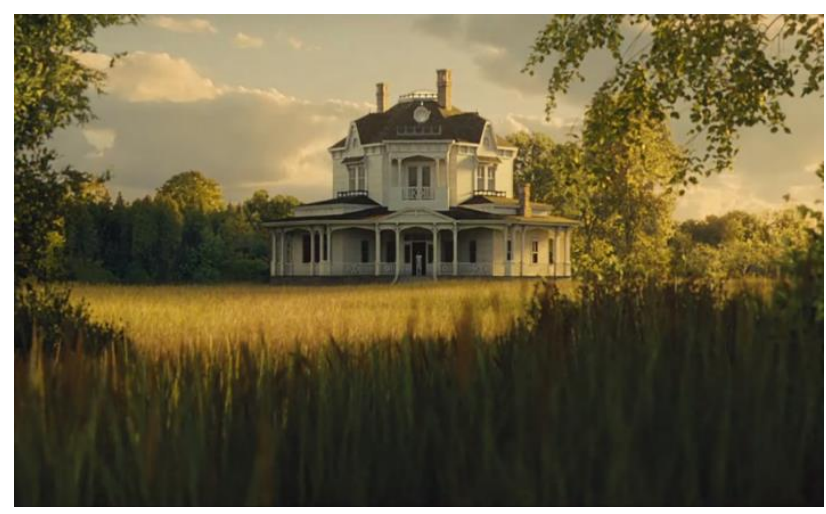

Fonte: Mãe! (2017)

No desenvolvimento de seus estudos a respeito do simbolismo do centro e da relação existente entre algumas edificações e a imagem do cosmo, Cavalcanti (2008) observa que para algumas culturas a arquitetura seria considerada uma ciência sagrada. Nessa interpretação, ela deveria ser desenvolvida a partir de medidas geométricas e matemáticas semelhantes àquelas que constituem o universo, das quais se originariam estruturas concebidas como cópias do arquétipo divino. Em outras palavras, o que se observa é que o gesto de criação realizado pelo homem no plano terreno repetiria, então, uma ação superior produzida por um deus num plano celestial.

Essa arquitetura sagrada, inspirada por um deus e que segue as medidas de uma edificação superior, pode ser observada no projeto de construção da casa em que a trama do filme de Aronofsky se desenvolve. Conforme se percebe ao longo da narrativa fílmica, e a partir da figura acima, a casa é construída no centro do território, simbolizando um universo particular por meio da repetição de arquétipos e de gestos paradigmáticos, semelhante ao que observa a estudiosa a respeito da compreensão da fundação do mundo em algumas culturas: "Muitas tradições culturais explicam a criação de um mundo como surgindo a partir de um Centro, concebido como um ponto ou como um círculo, no qual se deu, pela primeira vez, a manifestação da energia divina e a partir da qual o mundo é ordenado". (CAVALCANTI, 2008, p. 4). Desse modo, ela representa na história o próprio ponto de origem, o lugar onde a vida se principia, onde a realidade do mundo inicialmente se manifesta.

Considerando ainda uma associação com os arquétipos celestiais de territórios, seria possível afirmar que não é por acaso que a casa na qual vivem os protagonistas do filme se erija como uma edificação circular, com uma base esférica, completamente redonda em toda a sua extensão, como se representasse uma espécie de globo. É preciso lembrar que para muitas culturas e tradições espirituais, o formato arredondado relaciona-se, conforme observa Cavalcanti (2008, p. 17), a uma geometria sagrada, a uma estrutura interpretada como a mais perfeita, que estaria na origem da criação do mundo. Seguindo 
esse pensamento, a casa em Mãe!, com sua base circular e localizada no centro do terreno, seria lida como um protótipo do universo, conforme podemos notar a partir de uma visão do alto:

Figura 3 - Visão do alto do território da casa

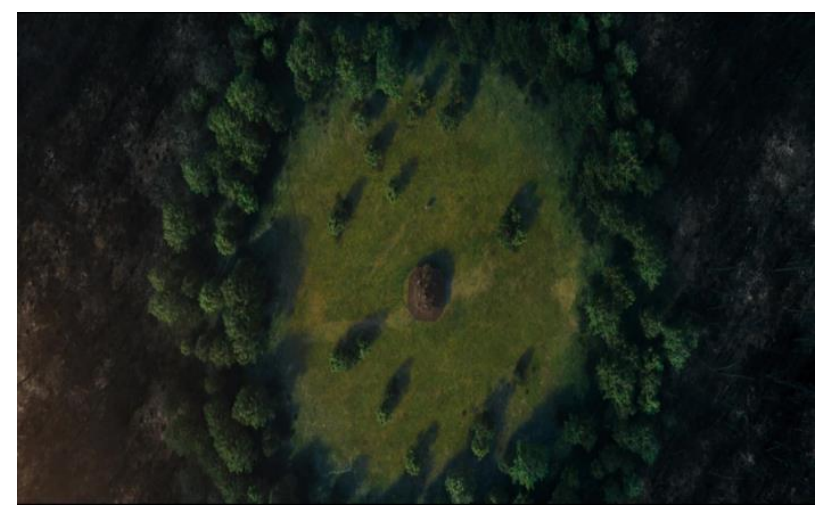

Fonte: Mãe! (2017)

Essa cosmicidade relacionada ao espaço da casa seria ratificada ainda no filme pela verticalidade de sua estrutura física responsável por criar uma hierarquia entre os lugares situados no baixo e aqueles localizados no alto da construção e que seriam reveladores das diversas funções de habitar. A esse respeito, Bachelard (2000) observa que o território da casa é formado por um corpo de imagens organizado a partir de dois temas considerados principais: " $1^{\circ}$ ) A casa é imaginada como um ser vertical. Ela se eleva. Ela se diferencia no sentido de sua verticalidade. É um dos apelos à nossa consciência de verticalidade; $2^{\circ}$ ) A casa é imaginada como um ser concentrado. Ela nos leva a uma consciência de centralidade”. (BACHELARD, 2000, p. 36). Numa leitura mítica, os dois temas se conjugam, associando a edificação à imagem do cosmo, a uma concepção geométrica do universo desenvolvida a partir de um centro ordenador e de um eixo vertical que ligaria o mundo superior, o mundo humano e o mundo inferior.

A arquitetura em vertical, conforme observa o filósofo, poderia ser compreendida, então, como uma espécie de eixo cósmico, semelhante à interpretação dada por muitas culturas ao símbolo da montanha. Nesse sentido, a casa, consoante aparece no filme, poderia ser tomada como uma coluna do mundo, que faria a ligação entre espacialidades opostas, apontando a partir de seu espaço mais elevado para o território do céu, o universo do sagrado, para uma realidade superior, enquanto o andar térreo faria referência ao plano da existência terrena, ao mundo dos homens. Por outro lado, o porão remeteria ao universo do oculto, das forças negativas, podendo traduzir, num contraste com os demais espaços, e para algumas culturas, a própria ideia de inferno.

Esses diferentes mundos ou realidades são percebidos no filme a partir da arquitetura da casa construída com um porão, um andar térreo e outro superior, tornando ainda mais complexa a leitura de 
seus espaços íntimos. Numa análise mais detalhada sobre a questão, o filósofo destaca a função da topoanálise como responsável pelo estudo psicológico dos lugares de nossa vida íntima, observando que “[...] quando a casa se complica um pouco, quando tem um porão e um sótão, cantos e corredores, nossas lembranças têm refúgios casa vez mais bem caracterizados”. (BACHELARD, 2000, p. 27, 28).

No filme, a compreensão desses espaços será fundamental para determinar uma associação com as ações dos personagens protagonistas, a mulher/mãe e o homem/poeta/escritor. Isso porque a territorialidade superior da casa aparece reservada para o poeta, constituindo-se como o seu lugar íntimo de criação, localidade quase secreta na qual apenas o escritor pode entrar e onde alegoricamente ele recria o próprio mundo por meio da palavra. Considerando a verticalidade da casa, a esse andar superior poderiam se associar aquelas mesmas características problematizadas por uma fenomenologia da imaginação, quando considera que "Com efeito, quase sem comentários, pode-se opor à racionalidade do teto à irracionalidade do porão". (BACHELARD, 2000, p. 36). Nesse sentido, a área mais alta da casa transforma-se na mais propícia para o sujeito escrever o mundo. Diferente do porão, das zonas inferiores, o andar superior é também aquele em que é possível projetar sonhos de maneira clara, na medida em que a visão do alto instiga o olhar a alcançar o infinito. O estudioso destaca que "Os andares elevados, o sótão, o sonhador os "edifica" e os reedifica bem edificados. Com os sonhos na altitude clara estamos, convém repetir, na zona racional dos projetos intelectualizados”. (BACHELARD, 2000, p. 37).

Convém problematizarmos ainda mais a cosmicidade do espaço da casa no filme dirigido por Aronofsky, quando compreendemos o papel do protagonista masculino como uma espécie de simulacrum $d e i$. Na função de escritor, ele é quem tem o poder de criação, o qual se manifesta, numa alusão ao texto bíblico e ao Deus Judaico-cristão, através da palavra. A deidade do personagem poeta será confirmada numa de suas falas finais dirigidas à mulher: "Eu sou o que sou, você era a casa", numa clara referência à passagem que aparece no livro do Êxodo, na qual Deus se dirige a Moisés, dizendo "Eu Sou o que Sou. É isto que você dirá aos israelitas: Eu Sou me enviou a vocês". (ÊXODO 3:14).

Dessa maneira, constituído por uma identificação verbal que semanticamente indica um estado de permanência, o personagem da narrativa fílmica caracteriza-se por mais um atributo divino, revelando a sua natureza imortal, a sua existência imperecível, razão pela qual sobrevive de uma temporalidade para outra, enquanto a protagonista feminina perece. A imortalidade do personagem e a restauração de um novo tempo, que se realiza numa passagem do caos para o cosmo, aparecem representadas em dois momentos do filme, no princípio e final da história, e se manifestam associadas a presença de uma pedra, uma espécie de cristal, guardada como um tesouro no mesmo ponto mais elevado da casa em que o escritor se recolhe para compor a sua obra, conforme demostrado na figura abaixo: 
Figura 4 - Pedra/cristal

Fonte: Mãe! (2017)

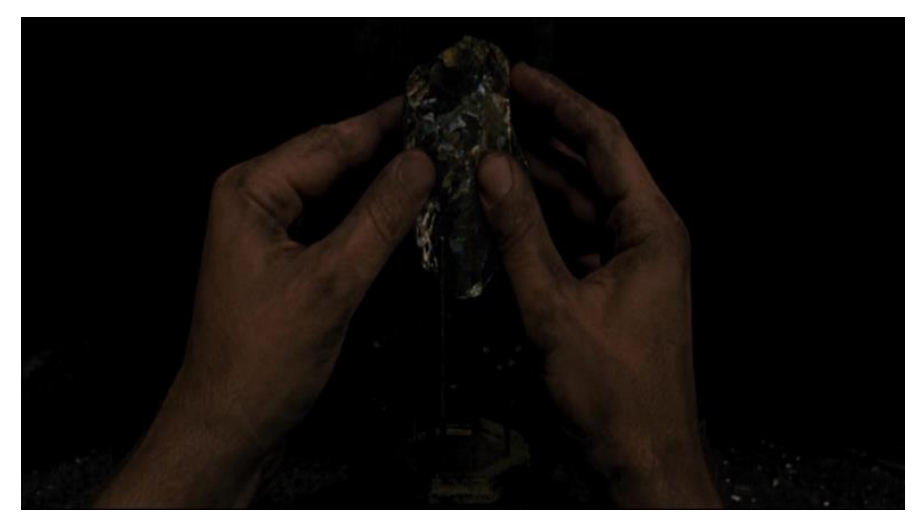

No primeiro momento, é possível observar a pedra/cristal logo depois da imagem da combustão representada na cena inicial do filme, quando ela é achada entre as cinzas e (re)colocada no lugar em que o personagem escritor destina para tal. Na sequência, a casa/cosmo aparece sendo restaurada, traduzindo uma relação entre este elemento e a reconstrução da territorialidade.

Numa leitura simbólica, Chevalier \& Gheerbrant (2009) observam que a pedra simboliza a fonte da criação. De acordo com relatos mitológicos, ela tem uma característica marcante no que tange à relação entre o céu e a terra. Os teóricos dos povos australianos e da indonésia, por exemplo, acreditam que as pedras de quartzo são fragmentos dos tronos celestiais caídos do céu aqui na terra, enquanto os sacerdotes xamãs utilizam essa pedra para poder ter o dom da clarividência. Em algumas culturas, acredita-se que pedras como o ônfalo trazem consigo a presença divina e remetem à simbologia do centro cósmico, à ligação dos canais do mundo do homem, dos mortos e dos deuses. Essa pedra teria o poder de criar mundos, da mesma maneira que ocorre com aquela que aparece representada em Mãe!. Por isso, ao final da narrativa, depois de um segundo cataclismo cósmico no espaço da casa, enquanto a mulher perece, o homem diz que precisar criar novamente o mundo, revelando que é a partir de sua figura que se manifesta na trama fílmica a expressão do sagrado, a partir da qual ele confabula a existência do cosmo com o auxílio da pedra/cristal retirada do peito da personagem feminina para iniciar um novo ciclo de criação.

Considerando ainda a simbologia universal da pedra, Freund (2008) destaca, em sua obra Mitos da Criação, uma antiga e conhecida história grega, na qual este elemento se relaciona com a criação da humanidade. Após a raça humana ser erradicada por um dilúvio, salvando-se apenas Deucalião, sua esposa Pirra e seu filho Prometeu, o casal entusiasmado para ter novos filhos, suplica a Zeus que atenda o vosso pedido. Assim, Zeus ordena que Deucalião e Pirra cubram seus rostos e lançem pedras sobre suas cabeças, estas se tornariam, respectivamente, homens e mulheres. Dentro desta mitologia, as pedras são tidas como “ossos da Grande Mãe, ou Mãe Terra”. (FREUND, 2008, p. 120). Seria possível, ainda, comparar a pedra do filme com a famosa pedra filosofal, criada pelo famoso alquimista Nicolas Flamel. 
Essa pedra é conhecida como "o pão do senhor", quem ela alcança pode ter a maravilha de ser rico, saudável e inteligente. A pedra filosofal "regenera a alma pela graça divina" (CHEVALIER, GHEERBRANT, 2009, p. 697-698).

Conforme se percebe, em diversos mitos e para muitas culturas, a imagem da pedra se relaciona, então, com o universo do sagrado, a criação da vida e o equilíbrio do mundo. No filme, é a partir dela que o cosmo e o caos se instauram como momentos divergentes na territorialidade da casa. Essa transição se desenrola pela chegada no lugar de um terceiro e quarto personagens, vividos pelo ator Ed Harris e pela atriz Michelle Pfeiffer. O homem, não cognominado, identificado apenas pela sua função de médico ortopedista, e sua esposa, inesperadamente, se alojam no lugar, e passam a desestabilizar a convivência do casal protagonista, desorganizando as suas rotinas: a personagem da mãe vai sendo obrigada a abandonar a reconstrução da casa, enquanto o poeta perde a inspiração e vai deixando para segundo plano a escrita do seu novo livro. Simbolicamente, a desordem se potencializa quando a personagem de Pfeiffer, sem permissão, invade os aposentos do escritor e provoca a quebra da pedra/cristal, instituindo definitivamente uma transformação na existência das pessoas que habitam a espacialidade da casa.

Essa transformação será mais significativa para a protagonista feminina, na medida em que, ao longo de toda a trama, ela é a personagem que parece manter uma relação mais estreita com a espacialidade da casa, responsabilizando-se, como já dissemos anteriormente, pela sua reconstrução. Esse vínculo antropocósmico se confirma ainda pelo fato dessa personagem, do princípio ao fim do enredo, não ultrapassar as fronteiras da territorialidade que habita, diferente do que ocorre com os demais sujeitos que realizam um movimento do interior para o exterior da morada, retornando na sequência das cenas.

Ao analisarmos fenomenologicamente essa relação da mulher com a casa, retomando as considerações a respeito de uma poética do espaço, será possível aprofundarmos ainda mais uma leitura sobre os valores relacionados à noção de ser abrigado na territorialidade do próprio lar. O pesquisador observa que "A vida começa bem, começa fechada, protegida, agasalhada no regaço da casa". (BACHELARD, 2000, p. 26). É numa condição semelhante a que destaca o estudioso que observamos a representação dos valores de intimidade no filme Mãel, sobretudo no desenrolar das primeiras cenas quando apenas o casal habita a moradia. Nessa circunstância, a casa é o local onde o homem e a mulher se sentem acolhidos, resguardados das adversidades exteriores, ao mesmo tempo em que sozinhos, um com o outro, se mostram à vontade, deixando a casa transbordar, também, uma geografia dos afetos responsável por instigar uma ação criativa a partir da qual o personagem escritor/poeta escreve o livro e a mulher reconstrói a casa, visando transformá-la num paraíso, enquanto sonha com a maternidade.

Dessa maneira, é possível afirmar que os significados das ações dos dois personagens protagonistas do filme, numa associação com a espacialidade da casa, se conjugam com o que observa o crítico ao afirmar que "Nessas condições, se nos perguntássemos qual o benefício mais precioso da casa, 
diríamos: a casa abriga o devaneio, a casa protege o sonhador, a casa permite sonhar em paz". (BACHELARD, 2000, p. 26).

Todavia, se por um lado o protagonista masculino se vincula ao espaço mais alto da casa, dada a sua função de escritor/poeta e a condição de representar ao longo da trama um simulacrum dei, conforme mencionamos anteriormente, a protagonista feminina, ao contrário, vai se relacionando cada vez mais ao território inferior da casa, passando a concentrar seus pensamentos, sentimentos e ações em direção ao porão. Esse fato se potencializa na medida em que a tranquilidade do ambiente vai sendo abalada pela presença de uma série de outros personagens, que a mulher considera como visitas indesejáveis e contra as quais passa a manifestar a sua sensação de incômodo, sem encontrar no marido o apoio para expulsar do lugar os intrusos e retomar a rotina anterior, quando apenas o casal habitava a morada.

A personagem de Jennifer Lawrence passa, então, a ver os seus sonhos desmoronarem, na medida em que a própria estrutura da casa vai igualmente sendo abalada. Num dos inúmeros episódios em que se desenrola um dos tantos clímaces da narrativa, observamos novamente o filme de Aronofsky reencenar mais um mito da tradição judaico-cristã, a partir do qual a antiga harmonia do lar é substituída por um fratricídio, que recupera a história de Caim e Abel trazendo à cena a reconhecida marca na testa do irmão assassino. A respeito desse acontecimento, importa-nos retomarmos uma problematização sobre a cosmicidade da casa, destacando a presença de uma segunda marca derivada também do assassinato entre irmãos e que aparece no assoalho do pavimento térreo como consequência do sangue que escorre em direção ao porão, consoante podemos notar pela imagem abaixo:

Figura 5 - Sangue escorrendo do pavimento térreo para o porão

Fonte: Mãe! (2017)

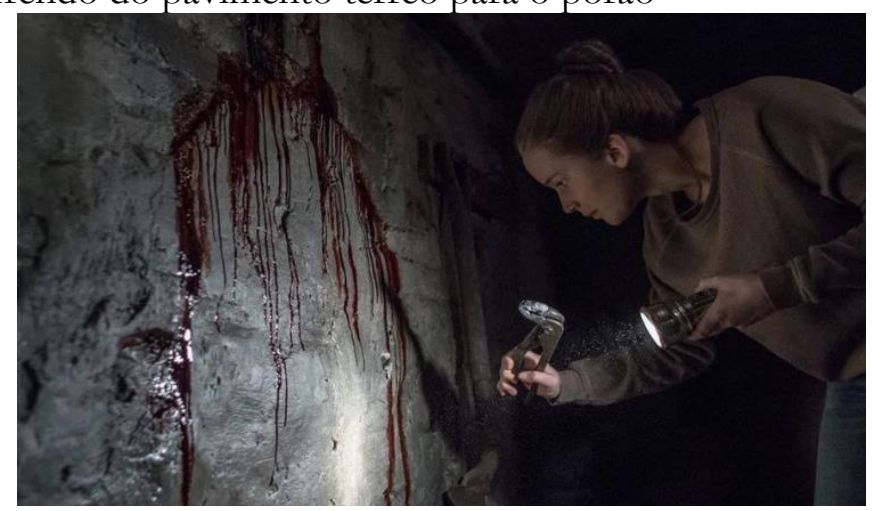

A mancha de sangue que a mulher procura a todo custo eliminar insistindo na limpeza ferrenha do piso, e depois escondendo-a por meio de um tapete, transforma-se no assinalamento dos seus temores, os quais a atraem a todo instante para os subterrâneos do porão. 
$\mathrm{Na}$ perspectiva de uma fenomenologia da imaginação, consoante desenvolve Bachelard (2000), o espaço do porão permite ao sujeito um agenciamento com as potências subterrâneas responsáveis por fazer emergir os medos mais primitivos do indivíduo humano e que são exagerados, nesse caso, pela ausência da luz, pela penumbra que se forma na transição do pavimento superior para as partes enterradas da casa, com paredes de um só lado e onde normalmente se guardam coisas velhas, sem serventia, esquecidas ao acaso ou propositadamente. Verticalizando o seu estudo a respeito das imagens suscitadas pelos territórios subterrâneos, o filósofo observa que "No porão agitam-se seres mais lentos, menos saltitantes, mais misteriosos. [...]. No porão há trevas dia e noite. [...] O porão é então a loucura enterrada, dramas murados" (BACHELARD, 2000, p. 37, 38).

Associando o sentido do porão ao da caverna platônica, poderíamos dizer que no filme Mãe! se reencena mais um mito da tradição filosófica, a partir do qual o subterrâneo da morada seria representado como o lugar da limitação da percepção, no qual o sujeito humano viveria em condição de ignorância, sempre distanciado da verdade. Essa leitura reafirma os significados relacionados à cosmicidade da casa, colocando em contraste os seus espaços mais extremos: o andar superior, onde o poeta se resguarda para criar a sua obra, e o andar inferior, que se apresenta constantemente para a mulher como uma ameaça. A esse respeito, é preciso destacar que na narrativa fílmica o porão é assombrado constantemente pela presença do fogo, cujas chamas aparecem inicialmente contidas numa fornalha, mas sempre lembrando a possibilidade de a casa ser mais uma vez consumida por uma combustão, como acabará por ocorrer ao final da história, retomando o mito apocalíptico.

Numa outra compreensão filosófica, o porão poderia ser interpretado não como o território das forças irracionais, mas, seguindo uma tradição a partir da qual se compreenderia os espaços das cavernas como uma antecâmara de um mundo subterrâneo, como o lugar no qual é possível adquirir conhecimento:

Filósofos gregos pré-socráticos, por exemplo, estavam fundamentados numa tradição da busca da sabedoria na escuridão, e não na luz, através da incubação de sonhos em cavernas. Aqueles que se iniciavam nesses lugares sagrados participavam de uma jornada no reino dos mortos na esperança de encontrar uma divindade que se tornaria seu amigo ou mentor. Tais cultos apresentavam a caverna como lugar de cura e conexão com o transcendental mundo para além dos nossos sentidos (NASSIF, 2011, n.p.).

Em diversas narrativas fílmicas, a escuridão da caverna é similar àquela representada pelos espaços subterrâneos do porão, das garagens estruturadas em subsolos, dos labirintos, onde o herói ou a heroína transita na iminência de ser atacado pelo vilão, mas para onde é necessário encaminhar-se para realizar uma viagem interior, um rito de iniciação que, ao mesmo tempo em que o coloca em confronto com os 
aspectos sombrios do lugar, com os seus próprios medos e faltas recalcadas, permite ao final obter um conhecimento especial, restabelecer a ordem do cosmos ou recuperar uma identidade perdida.

Em Mãe!, em certo sentido, o porão é o ponto de partida e de chegada, na medida em que é o espaço no qual se precipita o final e o começo da vida. Constituído de uma significação mítica, ele se torna o lugar no qual o expectador do filme observa, a partir de suas últimas cenas, mais uma conflagração do cosmo, representada por uma combustão que consome mais uma vez a casa, como demonstrado pela fotografia abaixo recortada:

Figura 6 - Casa após um novo cataclismo cósmico

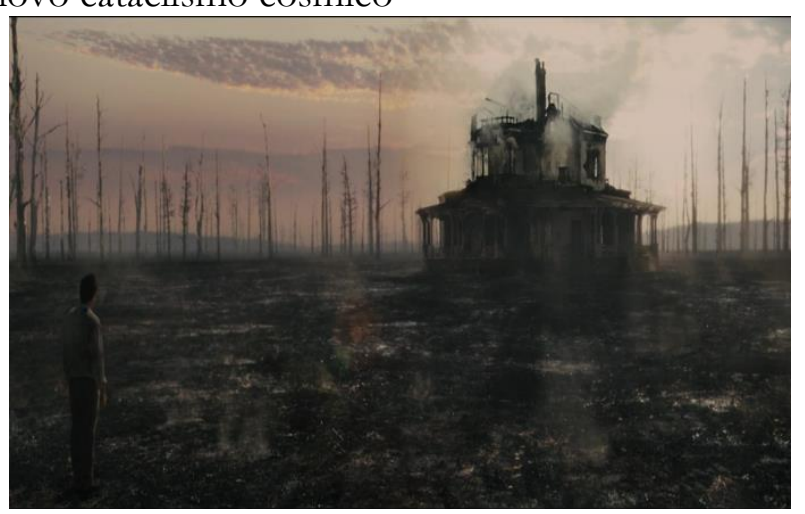

Fonte: Mãe! (2017)

Ao mesmo tempo, é a partir desse último advento que se observamos o restabelecimento da ordem, a qual é recuperada pelo sacrífico da vida da mulher e pela confirmação da deidade do personagem escritor, que sobrevive a temporalidade concreta, retomando o tempo mítico da criação e reeditando o mito do eterno retorno e da concepção do tempo circular.

\section{CONSIDERAÇÕES FINAIS}

Conforme procuramos demonstrar, o filme de Aronofsky reencena uma série de arquétipos da literatura universal, permitindo ao expectador retomar, a partir da representação da espacialidade da casa, imagens temáticas por meio das quais diferentes culturas contam, desde a temporalidade arcaica, a fundação do cosmo e dos sujeitos que nele habitam.

Essa tem sido, inclusive, uma temática recorrente na obra do referido diretor, como podemos observar a partir de uma análise dos seus principais filmes, nos quais Darren demonstra, por exemplo, um determinado interesse pelas escrituras bíblicas e seus mitos. Nessa perspectiva, em Mãe!, consoante procuramos identificar em nossa leitura, essas histórias vão sendo reencenadas do princípio ao fim da obra cinematográfica, da primeira à última cena da narrativa fílmica, cujo enredo é constituído retomando unidades primeiras da literatura universal, que servem ao roteirista para que ele possa representar o mito 
do eterno retorno e da concepção do tempo circular através de uma trama que se principia e finaliza por um cataclismo cósmico, a partir do qual se origina uma nova realidade.

Nessa passagem do caos para o cosmo, consideramos sobretudo em nossa leitura a importância da casa como uma morada sagrada, destacando como no filme ela se erige seguindo um protótipo divino de território manifestado a partir de sua arquitetura vertical, com espaços polarizados entre o alto e o baixo, e retomando o simbolismo do centro. Desse modo, pudemos refletir sobre a cosmicidade da habitação, problematizando, numa associação com as contribuições teóricas de Bachelard (2000), os significados de seus lugares vitais, do porão aos espaços mais elevados, para ressaltar a relação dos personagens protagonistas com cada uma das extremidades da casa. Considerando o exposto, ainda que o filme Mãe! tenha sido lançado a alguns poucos anos, quando recebeu boa recepção da crítica e do público, vale a pena ser (re)assistido e estudado na atualidade por amantes do cinema, estudantes das artes e das letras e, sobretudo, por sujeitos que gostam de histórias da origem dos homens e da vida, teorias religiosas, narrativas míticas e de uma tradição literária.

\section{REFERÊNCIAS}

BACHELARD G. A poética do Espaço. Editora Martins Fontes, São Paulo, 2000.

BÍBLIA de Jerusalém. Nova edição. Editora revista e ampliada. São Paulo: Paulus, 2002.

BÜHLER, R. D. A. Alegoria: antídoto na cena contemporânea da literatura brasileira. REVELL: Revista de Estudos Literários da UEMS, n. 1, p. 193-215, 2019.

CAVALCANTI, R. Os simbolos do Centro. Editora Perspectiva, São Paulo, 2008.

CHEVALIER, Jean; GHEERBRANT, A. (Trad.). Vera da Costa e Silva, v. 13, 1982. Dicionário de símbolos. 23a Edição. Rio de Janeiro: José Olympio, 2012.

ELIADE M. Mito do Eterno Retorno. 9ª edição, editora Mercuryo Ltda., São Paulo, 2007.

FREUND, P. Mitos da criação: as origens do universo nas religiões, na mitologia, na psicologia e na ciência. Editora Cultrix, São Paulo, 2008.

MÃE! Direção: Darren Aronofsky. Produção: Protozoa Pictures. EUA: Paramount Pictures, 2017. 1 DVD (2h 02min.).

NASSIF, L. Porões, Becos e Metrôs: a simbologia da caverna. O jornal de todos os Brasis. Disponível em: https://jornalggn.com.br/editoria/cultura/poroes-becos-e-metros-a-simbologia-da-caverna/. Acessado em: 20 de junho de 2021.

SILVA, J., FALCÃO, T. Distopia e Alegoria de Nosso Tempo: Explorando Jogos Vorazes. In: CONGRESSO BRASILEIRO DE CIÊNCIAS DA COMUNICAÇÃO, 42., 2019, Belém. Anais [...]. Belém: Intercom, 2019. 


\title{
Title
}

The cosmicity of the house: its myths and images in the movie Mother!, by Darren Aronofsky.

\begin{abstract}
This work aims to carry out a critical reading of the film Mother!, directed by Darren Aronofsky and released in the United States in 2017. Specifically, it intends to problematize about how a filmic narrative reenacts a series of myths from the universal literature, that unfold in the cinematographic version considering the symbolism of the territory of the house, which is understood as a particular universe that is related to a cosmic meaning, through which it comes to represent the world itself. In the development of our reflections, we resorted to studies in the mythology field, from the reading of theorists such as Mircea Eliade (2007) and Philip Freund (2008), and about the symbolism of the center, through the researches of Raissa Cavalcanti (2008) and Chevalier and Gheerbrant (2009), to highlight the dialogical relationships in the plot of Mother! and certain literary archetypes. We also focused, particularly, in the approach around the images of the house, carrying out a phenomenological analysis of its vital places with the theoretical support of Gaston Bachelard (2000), to demonstrate how the architecture of the house is erected from a polarity between the spaces above and below in the film.
\end{abstract}

\section{Keywords}

Darren Aronofsky; Mother!; myths; house.

Recebido em: 07/07/2021.

Aceito em: 20/08/2021. 